\title{
HEMORRAGIA DIGESTIVA POR TUMOR ESTROMAL GÁSTRICO
}

\section{GASTROINTESTINAL BLEEDING CAUSED BY GASTRIC STROMAL TUMOR}

\author{
Francisco de Souza Consolo ${ }^{1}$; Alexandre Augusto Pinto Cardoso, ACBC-SP²; \\ Odair Marcos Branco ${ }^{3}$; Henrique Lamego ${ }^{4}$; Laura Arruda ${ }^{5}$
}

\section{INTRODUÇÃO}

Em 1962 Stout $^{1}$ relatou os primeiros 69 casos de tumores não epiteliais gástricos de origem no musculo liso, e referiu-se a estes tumores como leiomioblastomas. A Organização Mundial de Saúde em 1969 caracterizou os tumores mesenquimais do trato grastrointetinal como: leiomioblastomas, leiomiomas, e leiomiossarcoma, sugerindo que estes se originam do músculo liso. Entretanto, com os recentes avanços de novas técnicas de ultra-sonografia e marcadores imunohistoquímicos, isso não foi possível ser demonstrado. Conseqüentemente, definiu-se que essas eram neoplasias de origem mesenquimal da parede do trato gastrointestinal, e passou-se então a utilizar o termo tumores estromais gastrointestinais (GIST), classificando os tumores de origem muscular lisa, nervosa, entre outros. A incidência de GIST é rara, aproximadamente entre 0,1 a $3 \%$ de todos os tumores gastrointestinais relatados. Muitos destes são descobertos no ato cirúrgico em quadros agudos. A recidiva é significativamente controversa devido ao seu alto aspecto maligno. Muitos estudos têm triado a identificação de fatores prognósticos corretamente, pois não há um método de acurácia para determinar pacientes de risco a recorrência. Estes tumores representam um grupo de lesão que tem uma dificuldade grande no seu diagnóstico, classificação e estratégia terapêutica.

\section{RELATO DO CASO}

C.R.T., 39 anos de idade, masculino, branco, solteiro, evangélico, natural de Paraíso do Norte, Paraná, residente na cidade de São Paulo há 15 anos. Foi resgatado, no dia 18 de setembro de 2003 em seu domicílio, e encaminhado ao Hospital da Aeronáutica de São Paulo (HASP), em estado de choque hipovolêmico devido à hemorragia digestiva alta profusa. Paciente relatou que apresentou melena quatro dias consecutivos antes do acontecido, mas achou irrelevante, quando então começou a apresentar astenia. Minutos antes do resgate apresentou hematêmese profusa que o levou à sínco- pe. Ao exame físico o paciente apresentava-se, confuso, informando apenas o episódio de hematêmese. Em mau estado geral, afebril, anictérico, acianótico, desidratado(2+/4+) e hipocorado(4+/4+), taquipneico, taquicardico, enchimento capilar maior que 5 segundos, pulsos periféricos simétricos, porém finos. PA: 80 x $20 \mathrm{mmHg}$, FC: 148 bpm, FR: 25 irpm, $\mathrm{T}^{\mathrm{o}}: 236,6^{\circ} \mathrm{C}$.

Aparelho respiratório e cardiovascular sem alterações. Abdome flácido, doloroso a palpação profunda em região epigástrica, sem massas palpáveis, com peristalse presente, sem sinais de irritação peritoneal. Membros inferiores sem alterações.

Exames Laboratoriais: (18/09/03)

Hemácias: 2.500.000; Hemoglobina: 7,1mg/dl; Hematócrito: 21\%; Leucograma: $17.510 \mathrm{cel} / \mathrm{mm} 3$; Metamielócitos: 3\%; Bastões: 10\%; Segmentados: 75\%; Linfócitos: 9\%; Monócitos: 2\%; Basófilos: 1\%. Uréia: $55 \mathrm{mg} /$ dl; Creatinina: 1,4 mg/dl; Na: 136mEq/dl; K: 4,0 mEq/dl.

Após a sua estabilização sob o ponto de vista hemodinâmico, o paciente foi encaminhado à endoscopia digestiva alta (EDA), que demonstrou: esôfago Normal. Estômago com presença de grande quantidade de sangue no seu interior, que foi aspirado, notando-se presença de lesão tumoral pulsátil com ulceração e sinais de sangramento ativo que não cessou após esclerose local. Duodeno sem alterações. (Figura1). Frente à não responsividade à esclerose da lesão e à nova instabilidade hemodinâmica optou-se pelo tratamento cirúrgico de emergência.

À laparotomia exploradora foi realizada gastrotomia longitudinal anterior, identificada lesão no fundo gástrico e realizada sua ressecção com grampeador longitudinal tipo Auto Suture Multifire GIA 80 (Titanium).

Após o procedimento cirúrgico o paciente foi encaminhado à unidade de terapia intensiva (UTI), manteve-se sob ventilação mecânica, desenvolveu complicações infecciosas que prolongaram sua permanência nesta unidade, mas com 35 dias pós-operatório teve alta da UTI, e com 41 dias de pós-operatório recebeu alta hospitalar. Sem sinais de recidivas do tumor.

\footnotetext{
1. Major Médico Cirurgião Geral; Chefe do Serviço de Cirurgia Geral do Hospital de Aeronáutica da São Paulo.

4. $2^{\circ}$ Tenente Médico do Hospital de Aeronáutica de São Paulo.

Recebido em 09/06/05

Aceito para publicação em 10/08/05

Conflito de interesses: nenhum

Fonte de financiamento: nenhuma

Trabalho realizado no Serviço de Cirurgia Geral do Hospital da Aeronáutica de São Paulo.
}

2. Capitão Médico Cirurgião Geral do Hospital da Aeronáutica de São Paulo; Professor da Escola Paulista de Medicina.

3. Médico; Ex-Aluno do Curso de Medicina da Universidade Estácio de Sá; Ex-Interno do Hospital da Aeronáutica de São Paulo.

5. Médica; Ex-aluna do Curso de Medicina da Universidade Gama Filho; Ex-Interna do Hospital da Aeronáutica de São Paulo. 

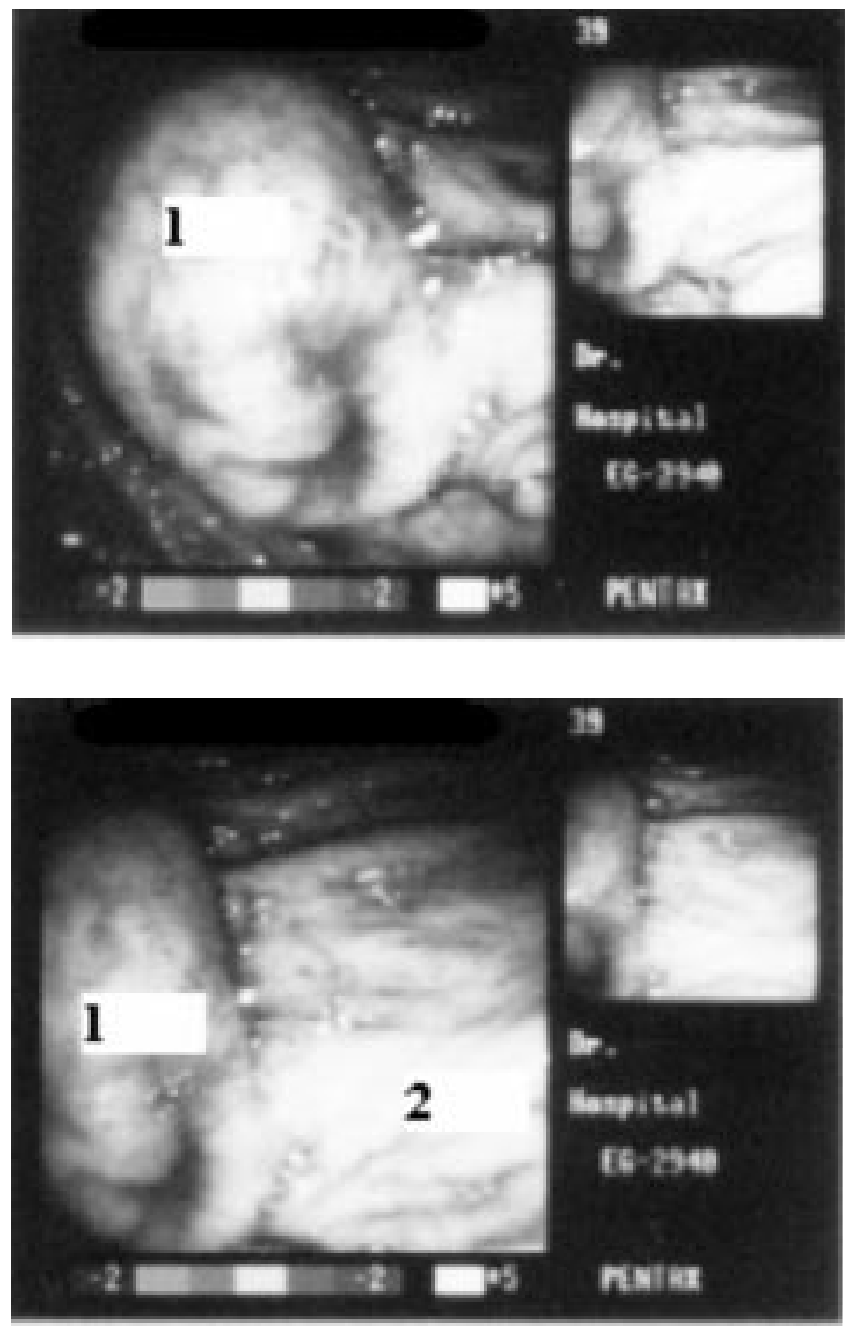

Figura 1 - Fotografia da endoscopia realizada de urgência em virgência de hemorragia digestiva alta, onde podemos observar: 1 Leiomioma gástrico com sinais de sangramento ativo; 2 - Leiomioma gástrico com mucosa normal.

O Exame anatomopatológico apresentou macroscopicamente: fundo de estômago com material representado por formação ovóide de tecido, referida como sendo proveniente de estômago, medindo 5,0x3,5x3,0cm. A superfície externa está recoberta por mucosa castanha que apresenta área deprimida medindo $0,8 \mathrm{~cm}$ no seu maior eixo. A superfície de corte é castanho-brancacenta de consistência firme elástica.

Ao exame microscópico os cortes mostram estômago apresentando mucosa adelgaçada e revestida por célula cilíndrica de núcleos típicos, tendo estroma com infiltrado linfoplasmocitário, vasos congestos e hemorragia. A mucosa está sobre elevada onde a parede tem lesão de crescimento expansivo e de limites nítidos, que é constituída por células mesenquimais em diferenciação muscular lisa. Não há malignidade. Laudo: Leiomioma Gástrico.

\section{DISCUSSÃO}

GISTs é o termo preferido para leiomioma, leiomioblastoma e leiomiossarcoma, porque estes apresentam a mesma linhagem indiferenciada, são encontrados geralmen- te entre a cinco e sete décadas de vida com uma incidência muito baixa, sem preferência por sexo ${ }^{4}$. Os tumores em sua maioria são assintomáticos. As manifestações mais comuns são: hemorragias gastrointestinais (sinal de malignidade), anemia, obstrução, compressão, dor, fadiga e melena. São as mais comuns massas submucosas do estômago, e representam $60 \%$ dos casos localizados no terço médio. $\mathrm{O}$ diagnóstico diferencial inclui: pâncreas heterotópico, tumor fibromatoso, cistos e lipomas. Eles geralmente não são encapsulados e apresentam dificuldade na diferenciação entre benigno e maligno. Características histológicas malignas podem ser vistas em 3 a $38 \%$ destes tumores, e não passam de $68 \%$ a presença de metástase. Alguns estudos têm sugerido determinantes tão bons quanto ao grau de diferenciação, ruptura do tumor, invasão por contigüidade de órgãos, para determinar o prognóstico de sobrevida. Por enquanto não existem métodos acurados para identificar o paciente com GIST no pré-operatório, e nenhum sistema de estadiamento. Fatores prognósticos como diferenciação histológica, localização, número de mitoses, tamanho, DNA anaplóide, fração S-fase, e atividade telomerase tem sido estudada. Assim como também outros estudos identificaram o c-KIT mutante em GIST sugestivos de tumores originados de células intersticiais simples.

A investigação laboratorial não é conclusiva para diagnóstico preciso pré-operatório, e marcadores específicos ainda estão em estudos. Obrigatoriamente eles têm crescimento intramural dificultando sua visualização por via endoscópica quando de pequeno porte, o que não é verdadeiro com a utilização da ultra-sonografia por via endoscópica e punção por agulha fina guiada por esta ${ }^{3,5}$. Estudos recentes mostraram que a Tomografia Computadorizada (TC) abdominal foi o teste mais específico, na avaliação pré-operatória ${ }^{1}$.

Cheng et $a l .{ }^{3}$ relataram que a ressecção cirúrgica para lesões pequenas e clinicamente insignificantes é desnecessária, e só retirar em casos de lesões grandes e sintomáticas.Os GIST são localizados na parede gástrica, com extensão ocasional intra e extragástrica. $\mathrm{O}$ método recomendado para ressecção, inclui 2 a $4 \mathrm{~cm}$ de margem de segurança para a incisão, enucleação, e ressecção gástrica formal. O procedimento deve ser realizado por laparotomia ou laparoscopia . Sabe-se que a localização da lesão é um importante fator para a ressecção, pois para as lesões situadas anteriormente utiliza-se a ressecção em forma de cunha, mas se for posterior realiza-se a gastrectomia e sua ressecção, quer intragástrica ou transgástrica. A técnica intragástrica deve ser preferida se o tumor se localizar na junção gastroesofágica com $2 \mathrm{~mm}$, e não é recomendada para tumores situados anteriormente ou para tumores com extensão extragástrica. Estudos recentes demonstram a ampla vantagem de utilizar a laparoscopia associada com endoscopia per-operatória ${ }^{2,4}$ Com essa técnica possibilita a ressecção destes tumores tanto anteriores quanto posteriores, e com pequenas variações dessa técnica é possível ressecar tumores da junção gastroesofágica ${ }^{4}$.

Os achados histopatológicos relevantes são: tamanho que varia entre 0,8 à $23 \mathrm{~cm}$, mitoses $(42 \%)$, ulceração e necrose $(53 \%)$, alta celularidade $(20 \%)$, pleomorfismo nuclear $(50 \%)$, invasão de órgãos adjacentes $(1 \%)$, metástase $(1 \%)^{2}$. Os 
marcadores imunohistoquímicas positivos são: vincristina, desmiosina, actina, S-100, CD 34². Mas verificou-se que só baseado nesses dados histopatológicos, há um equilíbrio entre a malignidade e benignidade destes tumores, $53 \%$ para $47 \%$, respectivamente. Estudos recentes revelam a presença de um anticorpo agonista direto de antígeno de proliferação (Ki67) que é detectado pela técnica PCNA, e esta correlacionada com achado mitótico e necrótico, mas este é restrito devido à complexidade de sua técnica ${ }^{2}$. Outros marcadores nucleares de células tumorais são definidos com MIB-1, que indica maior agressividade da progressão do tumor, em relação ao p53 positivo. Outro achado demonstra que a mutação do exon 11 do cKit oncogênico correlaciona-se com a sobrevida. Com isso são utilizados parâmetros associados para determinar o risco de sobrevida do paciente ${ }^{2}$. O baixo risco é definido com achado menor que $10 \%$ de mitoses, e tamanho menor que $5 \mathrm{~cm}$; um risco intermediário pode ser considerado quando obsevar mitoses entre 10 e $20 \%$; e alto risco quando o tumor é maior que $5 \mathrm{~cm}$ e mais de $20 \%$ de mitose $^{2}$.
A evolução de todos estudos analisados foi significativamente satisfatória sem evidência de recidiva da doença, com exceção de um paciente que apresentou recidiva após 24 meses, isso porque seu tumor primário tinha mais de $10 \mathrm{~cm}$ de diâmetro e mitose maior que $30 \%{ }^{2}$; e outro paciente que teve hemorragia digestiva alta volumosa, que evoluiu com choque hipovolêmico e coagulação intravascular disseminada, chegando ao óbito ${ }^{4}$.

A dificuldade de estabelecer um diagnóstico preciso pré-operatório é refletida sobre o tipo e extensão da terapia cirúrgica, e até mesmo o prognóstico do curso clínico. Essa situação, foi comprovada neste relato de caso. Em contrapartida, verificamos que com o desenvolvimento de técnicas cirúrgicas eficazes, que se baseiam na ressecção completa do tumor antes da localização avançada da doença, têm se mostrado ser um método de escolha de opção terapêutica para esses pacientes, por ter apontado melhor sobrevida.

Devemos ainda ter em mente este tipo de entidade nosológica quando abordarmos um paciente portador de hemorragia digestiva alta.

\begin{abstract}
Gastrointestinal stromal tumors account for 0.1 to $3 \%$ of all resected gastric tumors and are the most common submucosal mass found in the stomach. Preoperative diagnosis is often difficult; consequently surgery is the best and only option on most cases. There are studies with different surgery techniques based on tumors location. The reported case led us at literature review with the intent of establishing preoperative diagnosis, therapeutic strategies and prognosis (Rev. Col. Bras. Cir. 2007; 34(1): 64-66).
\end{abstract}

Key words: Leiomyoma; Stromal cells; Stomach neoplasms; Gastrointestinal hemorrhage.

\section{REFERÊNCIAS}

1. Golden T, Stout AP. Smooth muscle tumours of the gastrointestinal tract and retroperitoneal tissues. Surg Gynecol Obstet .1941; 73; 784-90.

2. Xu GQ, Zhang BL, Li YM, Chen LH, Ji F, Chen WX, Cai SP. Diagnostic value of endoscopic ultrasonography for gastrointestinal leiomyoma. World J Gastroenterol. 2003;9(9):20088-91.

3. Okai T, Minamoto T, Ohtsubo K, Minato H, Kurumaya H, Oda Y, Mai M, Sawabu N. Endosonographic evaluation of c-kitpositive gastrointestinal stromal tumor. Abdom Imaging. 2003;28(3):301-7.

4. Bouillot JL, Bresler L, Fagniez PL, Samama G, Champault G, Parent Y. [Laparoscopic resection of benign submucosal stomach tumors. A reported 65 cases]. Gastroenterol Clin Biol. 2003;27(3 Pt 1):272-6.
5. Mattheus BD, Walsh RM, Kercher KW, Sing RF, Pratt BL, Answini GA, Heniford BT. Laparoscopic vs open resection of gastric stromal tumors. Surg Endosc. 2002; 16(5):803-7. Epub 2002 Feb 8.

Como citar este artigo:

Consolo FS, Cardoso AAP, Branco OM, Lamego H, Arruda L. Hemorragia digestiva por tumor estromal gástrico: relato de caso. Rev Col Bras Cir. [periódico na Internet] 2007; 34(1). Disponível em URL: http://www.scielo.br/rcbc

Endereço para correspondência:

Alexandre Augusto Pinto Cardoso

Av. Braz Leme, 3046 - Bl. 10 - apto. 201

Santana

02022-001 - São Paulo - SP

E-mail: aapc.morf@epm.com 